Portland State University

PDXScholar

\title{
The Contrast of Covariational Reasoning and Other Problem Solving Methods of a Calculus Student
}

Micah Kurzer

Portland State University

Follow this and additional works at: https://pdxscholar.library.pdx.edu/honorstheses

Let us know how access to this document benefits you.

\section{Recommended Citation}

Kurzer, Micah, "The Contrast of Covariational Reasoning and Other Problem Solving Methods of a Calculus Student" (2018). University Honors Theses. Paper 594.

https://doi.org/10.15760/honors.603

This Thesis is brought to you for free and open access. It has been accepted for inclusion in University Honors Theses by an authorized administrator of PDXScholar. Please contact us if we can make this document more accessible: pdxscholar@pdx.edu. 
The Contrast of Covariational Reasoning

and Other Problem Solving Methods of a Calculus Student

by

Micah Kurzer

An undergraduate honors thesis submitted in partial fulfillment of the

\author{
requirements for the degree of \\ Bachelor of Science \\ in \\ University Honors \\ and \\ Mathematics
}

Thesis Adviser

Steven Boyce

Portland State University 


\begin{abstract}
Research has shown that covariational reasoning is indicative of success across a variety of mathematics topics, especially calculus. This paper will build on the prior research by examining one calculus student's covariational reasoning over a multiple term teaching experiment. The tasks associated with the teaching experiment appear in a variety of mathematical forms, and in varying contexts, so that the student's techniques for each task provide results that can be interpreted using existing frameworks. Analyzing the covariational reasoning of the student with these frameworks reveals relationships between the methods the student uses to solve tasks involving covariational reasoning and the student's abilities to successfully solve the tasks.
\end{abstract}




\section{Introduction}

Covariational reasoning is a subject many students have never even heard of, and yet is one that they use regularly in their mathematics courses and their lives. People interact with covariational reasoning frequently because it is simply the ability to consider how two quantities are varying in reference to each other (Carlson, Jacobs, Coe, Larsen, \& Hsu, 2002). The importance of covariational reasoning to calculus and other mathematics courses should not be understated, as research has shown it to be highly indicative of success in calculus and other higher level mathematics courses (Carlson, Oehrtman, \& Engelke, 2010). Covariational reasoning also provides insight into any other field that requires an understanding of how quantities relate to each other, whether being used to provide validity to research, or to provide a greater depth of knowledge. Covariation is often present in many situations in the non-academic world as well, with many people regularly encountering it and solving problems related to it. Despite this, it seems as though many people are unable to fully understand it and apply it across contexts.

For mathematics students, researchers have shown that those with lower covariational reasoning have gaps in their knowledge that often limit their abilities to solve diverse sets of problems across a variety of contexts (Byerley, Yoon, \& Thompson, 2016; Johnson, 2012; Moore \& Carlson, 2012 ; Paoletti, Stevens, Hobson, Moore, \& LaForest, 2017; Thompson, 2012; Weber \& Thompson, 2014; etc.). This is thought to be a contributing factor to the high rates of failing calculus students across U.S. universities (Carlson et al. 2010). The research indicates a lack of covariational reasoning being applied by students in schools, yet those who are able to show higher levels of covariational reasoning are likely successful in their mathematics courses. 
This is why it is an important subject of research. The concerning nature of the research on covariational reasoning is the gap between the importance of covariational reasoning and the lack of education for it.

While the issues surrounding education around covariation may be broad, this paper will examine how a calculus student uses his covariational reasoning as well as other methods of problem solving in order to solve a variety of tasks. To consider the covariational reasoning the student portrays in a given task, covariational reasoning must first be defined. The starting definition of covariational reasoning for this paper relies on the student's behaviors related to imagining two quantities changing in relation to one another (Carlson et al., 2002). While this will be attended to in more depth shortly, the reader who has not heard of covariational reasoning could take this definition and apply it to the real world situation involved with driving a car below.

When driving in most cars there are at least three tools that can be combined using covariational reasoning, and when combined this way describe more complex situations. The three tools examined here are the clock, the odometer and the speedometer. When considering how fast one is going there are multiple ways to determine it using these tools. Generally one would look at the speedometer, which would give them a speed, a relationship between a unit of distance and a unit of time. In addition to this a creative person could also take it upon themselves to check the odometer at two different times and calculate the average speed over that time frame. Even when considering the time it would take to drive to a location given an average speed, many people would apply their covariational reasoning without noticing it, and would actually inadvertently be performing a task related to calculus. 
The inherent understanding, yet unawareness of covariational reasoning found in students makes it hard to determine how they are using their covariational reasoning and how they are not. Fortunately, there are many researchers working on just this examination of how to describe covariational reasoning. Much of the current research on covariational reasoning examines how students' covariational reasoning limits or aids their mathematical skills across a variety of contexts and mathematical representations. There are currently in depth frameworks with levels of covariational reasoning (Carlson et al. 2002), and examinations of many other mathematical concepts as related to covariational reasoning including; parametric functions (Paoletti \& Moore 2017), quantities (Thompson 2012), accumulation (Thompson \& Silverman, 2008) and polar coordinates (Moore, Paoletti, \& Musgrave, 2013). These pieces of research provide tools for examining the student's covariational reasoning over the course of the teaching experiment used in this paper.

The following sections of this paper will provide a description of the student's covariational reasoning using frameworks from previous research. When modeling the student's reasoning it is the goal of this paper to examine the degree to which the methods used by the student in solving the problems are helpful to his mathematical success. The methods, results, and discussion all reflect this goal to understand where covariational reasoning is used and where other methods, of varying levels of success, are used. This paper will hopefully be able to provide insight into how this student, and similar students, have learned mathematics and how this affects their mathematical abilities. 


\section{Theoretical Background}

To start one can recall the earlier brief definition of covariational reasoning, which provided a description involving quantities. To build up to that definition this paper will first address what quantitative reasoning is. Thompson (2012) addresses quantitative reasoning as the mental actions involved in; finding a measurable attribute, constructing a unit of measure for that attribute, and providing an understanding of a process to measure it. The measurement process means the student needs to understand; what one would have to do to measure the quantity, what is the concept being measured, and what the resulting measurement actually means. This definition is important to this research, as covariational reasoning first relies on the students' understandings of the quantities on their own.

Moving to the main subject of the paper is covariational reasoning, which has many definitions and components that are a part of it. This paper emphasizes that covariational reasoning is a student's ability to apply their schemes and knowledge associated with quantities such that they can coordinate two quantities varying together (Thompson, 2012). There are multiple definitions with different focuses that will be discussed.

Thompson (2012) introduces covariational reasoning similarly to the initial definition used in this paper, as a student's coordination of two quantities, but includes the addition of constructing these quantities over conceptual time. Conceptual time is described as an imagined passage of incremental, but infinitely small, time within a problem. This type of reasoning is often used in tasks containing real world situations, as students perceive time as inherent in the other quantities varying. The implied nature of conceptual time create difficulties in determining covariational reasoning, like when students are asked to perform tasks such as relating volume to 
height of a water bottle as it is filled and instead a student relates height to time and volume to time (Weber \& Thompson, 2014; Paoletti \& Moore, 2017).

Another definition related to covariational reasoning (Thompson, 1994) includes three phases of a mature image of rate of change. From the perspective of this research a mature image of rate of change is defined in parts as; constructing a change in one quantity as some image, coordinating two changing quantities' images with each other, and forming a simultaneous image of the covarying nature of the two quantities. This definition of rate of change relates to the parametrization used with conceptual time above, and the entire definition provided here gives context to the next view of covariational reasoning, which was based on this definition.

In the primary source used in this paper to describe covariational reasoning, it is defined as, "coordinating two varying quantities while attending to the ways in which they change in relation to each other" (Carlson et al. 2002). The research goes further and provides a specific table (Table 1), provided later in the methods section, with five mental actions related to covariational reasoning, and the behaviors exhibited to match them. Within this framework there are five levels of covariational reasoning supplied, which relate to a student's ability to portray a mental action around covariational reasoning as well as all the mental actions that are numerically lower. Carlson et al. (2002)'s research has conveyed a systematic approach to the research on covariational reasoning, as well as the covariational frameworks containing numerous subtleties for other researchers to examine more in depth.

One of such subtleties examined in Carlson et al. (2002) is pseudo-analytical thinking. This concept is also used in other research, and often defined as thought processes that are memorized and repeated by the students without them acknowledging contexts where it does not 
apply (Carlson et al. 2002; Thompson \& Silverman, 2008). Research on mathematical reasoning have discussed the concept of pseudo-analytical thinking as a source of behaviors that the student has when they use words and actions in ways that are not specific to the problem (Thompson \& Silverman, 2008). For example, pseudo-analytical behavior has also been described by the ways the student may explain the accumulation function, and how it can pseudo-analytical behavior if the exact same explanation of accumulation would be true for a explanation of area (Thompson \& Silverman, 2008). Other research has described pseudo-analytic behavior as behaving in a consistent manner with a framework, but when being asked follow up questions lacking the underlying reasoning inherent to the framework (Carlson et al., 2002).

Within this paper there is some thought that process and action views, which are two different approaches and ways of thinking about functions, can be a part of a student's pseudo-analytical thinking. An action view of a function can occur when a student is unable to view a function more broadly than what is given by specific results and is often only able to consider input and output results individually (Oehrtman, Carlson, \& Thompson, 2008). This same research has shown an action view to often lead the student to see the function as something to plug a number into and calculate a result, with little more thought to the function. An action view of a function can also be expressed by the way a student reasons about inverses, where a student with an action view of a function would commonly switch the $x$ and $y$ variables in an equation and solve for $y$. This reasoning around inverses often involves no conception of the reverse input to output process being created. The process view of a function is the contrast, which involves the student viewing the function as a transformation or a mapping of a continuum of outputs and a continuum of inputs (Oehrtman et al., 2008). As opposed to the action view, 
students who use a process view think this set of input and output values defined by the function and when they find the inverse see this as more than switching and solving, but as a mapping of the outputs back to the inputs.

The next concept that is a part of pseudo-analytical thinking is the concept of shape thinking (Moore \& Thompson, 2015). In the research on it, shape thinking focuses on what the graph means to the student, and splits it into two categories of static shape thinking and emergent shape thinking. Static shape thinking is treating the graph first as an object with physical properties and perceptual cues (Moore \& Thompson, 2015). Their research argues that this results in a student constructing the same reasoning about the shape of line no matter the presence of different coordinate systems, different orientation, or other aspects that would make the graph have a different mathematical relationship. This research contrasts static shape thinking with emergent shape thinking, where a graph is viewed as an object with physical traits, but one that inherently depicts mathematical attributes of some kind of relationship. Often emergent shape thinking includes some amount of covariational reasoning, as the graph being thought of as a record that tracks the way the quantities relate to each other (Moore \& Thompson, 2015).

There are additional aspects of student's covariational reasoning related to the background above, but many of them were not widely applicable to the sections of videos analyzed for this paper. While they will not be included in depth in the coding process these were considered when analyzing the student's reasoning. One such piece of research involves viewing understandings of slope as "chunky" or "smooth" (Byerley et al. 2016), which closely related to distinctions between mental actions 4 and 5 from the framework of Carlson et al. (2002). An 
additional connection to covariational reasoning related to, but different from, shape thinking are more discussions into the concepts of transformational reasoning and orientation, and the relation of these subjects to the covariational reasoning present in the students (Johnson, 2012). Additionally, there are codes and research on graphs involving applying the concepts of covariational reasoning to multiple coordinate systems, such as polar coordinates (Moore et al. 2013). This is briefly examined when analyzing Trevor's covariational reasoning in alternate graphical systems. Each of these articles relates to, and interacts with one another in ways to determine what is covariational reasoning, and how can one model attributes of it.

\section{Methods}

\section{Data Sources}

The analysis in this paper was formed from viewing the video recordings of four separate hour long experiment sessions. The four videos analyzed in this paper were a subset of the sessions from a larger experiment, chosen based on the types of tasks examined by the student, and the covariational reasoning used by the student. For the experiment, constructivist teaching experiment methodology (Steffe \& Ulrich, 2014) was employed. This method focuses on modeling students' thinking and the changes in thinking encountered across contexts and representations (Steffe \& Ulrich 2014). This included investigating students' ways of operating with their knowledge while acknowledging and avoiding the influences of the researcher's own ways of operating. The theoretical approach of the constructivist teaching experiment was used for this research, as it provided the understanding of the researcher's attempts to model the students' behavior, while recognizing outside influences upon the student. Each session included 
tasks for the student which were carefully chosen, created, or altered to help model specific aspects of the students' understandings of various mathematical concepts across various contexts. This work has been done by the other researchers participating in the project.

This paper focused on an individual calculus student, referred to in this paper as Trevor, who was present in all four sessions viewed. The student involved in these sessions was taking differential and integral calculus over the course of the multiple term experiment sessions. The teacher and researcher facilitating each session was a mathematics education research faculty member. Also present in the sessions was a witness (Steffe \& Ulrich, 2014), and in one of the examined sessions another student from the experiment, referred to as D, was also present. Trevor was often paired with D in the sessions of the larger teaching experiment, but as Trevor was the focus for this analysis there is only one video examined where $\mathrm{D}$ was present. To initially choose which student to be the focus of this paper, I viewed a single video that covered a one hour session including both Trevor and D, and based on some initial notes on the covariational reasoning employed by the students chose to further examine Trevor's covariational reasoning.

\section{Analysis}

As with the constructivist teaching experiment, the analysis done for this paper involved identifying unanticipated ways of operating (Steffe \& Ulrich, 2014). This also involved determining if these were viable adaptations to the task, or if there is an essential lack of knowledge. Then I explored how these ways of operating are limited across various contexts and modeling all of these aspects. The constant comparative method (herein referred to as CCM) 
(Boeije, 2002) is an aspect of qualitative research with its roots in the grounded theory approach (Glaser \& Strauss, 1967) and was used as the framework for this paper's recursive analysis. The methodology of the CCM was chosen as it is used to compare qualitative data in a structured and systematic way. This recursive analysis involved open coding, coding for types of behavior, and axial coding, comparing open codes between the video sessions (Boeije, 2002). Through an iterative process the open and axial codes were refined to create themes (Boeje, 2002), and using these themes to model the viability of the student's ways of operating (Steffe \& Ulrich, 2014).

After choosing a student to be the focus of the research based on the session including two students, I began to watch other sessions. While examining these sessions I would watch one at a time, beginning with a video chosen by the researchers based on my notes on Trevor's covariational reasoning from the previous video. These notes were comprised of important sections of the session being examined that were connected to Trevor's covariational reasoning. Then I would bring these notes to other researchers on the larger teaching experiment as to their thoughts on the sections, and we would discuss any differences in viewing it. After doing this for one session, the researchers and I would discuss what sessions from the experiment might be useful to either build off of the notes I had taken, or construct depth to the results from that individual session. Additionally, if the researchers had a different way of viewing a session based on their knowledge of all the sessions they would consider that in choosing the next session for me to watch. Repeating this two more times I constructed initial notes that described sections of Trevor's covariational reasoning across four of the teaching experiment sessions.

I then took the notes across these four sessions and reviewed them for an initial round of open coding. I examined the important sections involving covariational reasoning earlier 
identified in my notes, approximately 10 per video and 40 total, using open codes about the student's reasoning, as well as the context of the problem. Most of these open codes were based on previous research and concepts in the theoretical background. Any section where it was difficult to determine the code, I would first review the codes to see if they inherently did not apply to the section. Then if that was not the case I would get feedback from other researchers on how I coded that section and take notes on differences in coding. Following this I examined the open codes as a whole to look for connections and relationships to specific contexts or representations. After this axial coding, I returned to my initial codes to determine where the initial set of open codes did not fit the themes found in the axial coding, or if there were themes in the axial coding that needed to be better described in open coding. After refining the open codes based on the sections above, I again applied them to the sections involving covariational reasoning. This was repeated until there was a list of refined open codes that were coded by other researchers the same ways. Then these open codes were carefully compared to each other and to themselves across the sessions to create themes.

The refined open codes dealt with three main portions of Trevor's reasoning. The first was most directly his covariational reasoning, in which the covariational reasoning framework (Carlson et al, 2002), included below (Table 1), was used to determine what level of covariational reasoning Trevor was displaying based on a variety of behaviors. The next category of coding referred to Trevor's pseudo-analytical thinking, which while not directly part of the covariation framework, is included in the original research. In the framework provided if pseudo-analytical thought is observed it can override the level of covariational reasoning previously determined. This pseudo-analytical thinking related to whether the student's 
adaptations were viable (Steffe \& Ulrich, 2014). Then working through the pseudo-analytical codes, it was subcategorized to create two primary categories that were also coded.

The first of these two categories was the distinction between static and emergent shape thinking (Moore \& Thompson, 2015). This code relied on determining if the student treats the graph as an object whose physical properties and shape determine the graph, or if the graph is viewed as a representation of a relationship of quantities (Moore \& Thompson, 2015). Static shape thinking involves the student's actions being based on perceptual cues of the graph and attributing properties to a graph based on its shape, whereas emergent shape thinking views the graph as a visual depiction and record of covarying quantities of a function (Moore \& Thompson, 2015). These behaviors were looked for and coded where appropriate.

The second pseudo analytical thinking related code was the distinguishing process and action views of the function in the student. This code was determined by whether or not the student treated the function(s) involved in a task as plugging in an input and getting out an output, or if they considered it to be a continuum of such values (Oehrtman et al., 2008). In this code an action view was determined by the treatment of a function as an action where it would give a specific output for a specific input. It was alternatively coded as a process view if there was evidence of viewing the function as determining a process between the input and output where each input will give an output, as well as the function being viewed as a mapping of all inputs to all outputs (Oehrtman et al., 2008) (for more descriptions on the differences between action and process views of functions see Appendix A).

The final major category for my coding was reliant on the representation and context of the task itself, and the objects Trevor created while solving the task. This first included 
distinguishing function types, such as linear, trigonometric, quadratic, derivative, and integral, as well as compositions of them, like the integral of a trigonometric function. Also included in this category was the representations for the task itself, and representations created by the researcher and the representations Trevor created himself. These types of representation were; algebraic, which included equations of functions, tabular, which included listed values of functions at specific points, verbal, which included contextual word problems, and graphical, which was split into two categories one having axis which was referred to as "graphical", and the other not having axis which was referred to as "other visual" in the codes.

Mental Actions of the Covariation Framework

\begin{tabular}{|c|c|c|}
\hline Mental action & Description of mental action & Behaviors \\
\hline $\begin{array}{l}\text { Mental Action } 1 \\
\text { (MA1) }\end{array}$ & $\begin{array}{l}\text { Coordinating the value of } \\
\text { one variable with changes } \\
\text { in the other }\end{array}$ & $\begin{array}{l}\text { - Labeling the axes with verbal indica- } \\
\text { tions of coordinating the two variables } \\
\text { (e.g., } y \text { changes with changes in } x \text { ) }\end{array}$ \\
\hline $\begin{array}{l}\text { Mental Action } 2 \\
\text { (MA2) }\end{array}$ & $\begin{array}{l}\text { Coordinating the direction } \\
\text { of change of one variable } \\
\text { with changes in the other } \\
\text { variable }\end{array}$ & $\begin{array}{l}\text { - Constructing an increasing straight } \\
\text { line } \\
\text { - Verbalizing an awareness of the di- } \\
\text { rection of change of the output while } \\
\text { considering changes in the input }\end{array}$ \\
\hline $\begin{array}{l}\text { Mental Action } 3 \\
\text { (MA3) }\end{array}$ & $\begin{array}{l}\text { Coordinating the amount } \\
\text { of change of one variable } \\
\text { with changes in the other } \\
\text { variable }\end{array}$ & $\begin{array}{l}\text { - Plotting points/constructing secant } \\
\text { lines } \\
\text { - Verbalizing an awareness of the } \\
\text { amount of change of the output } \\
\text { while considering changes in the } \\
\text { input }\end{array}$ \\
\hline $\begin{array}{l}\text { Mental Action } 4 \\
\text { (MA4) }\end{array}$ & $\begin{array}{l}\text { Coordinating the average } \\
\text { rate-of-change of the func- } \\
\text { tion with uniform incre- } \\
\text { ments of change in the } \\
\text { input variable. }\end{array}$ & $\begin{array}{l}\text { - Constructing contiguous secant lines } \\
\text { for the domain } \\
\text { - Verbalizing an awareness of the rate } \\
\text { of change of the output (with respect } \\
\text { to the input) while considering uni- } \\
\text { form increments of the input }\end{array}$ \\
\hline $\begin{array}{l}\text { Mental Action } 5 \\
\text { (MA5) }\end{array}$ & $\begin{array}{l}\text { Coordinating the instanta- } \\
\text { neous rate of change of the } \\
\text { function with continuous } \\
\text { changes in the independent } \\
\text { variable for the entire } \\
\text { domain of the function }\end{array}$ & $\begin{array}{l}\text { - Constructing a smooth curve with } \\
\text { clear indications of concavity changes } \\
\text { - Verbalizing an awareness of the in- } \\
\text { stantaneous changes in the rate of } \\
\text { change for the entire domain of the } \\
\text { function (direction of concavities and } \\
\text { inflection points are correct) }\end{array}$ \\
\hline
\end{tabular}

Figure 1. Mental Actions of the Covariational Framework. Includes descriptions and behaviors associated with various levels of covariational reasoning (Carlson et al., 2010). 


\section{Application of coding: Trevor's use of shape thinking and covariational reasoning.}

In the following excerpt, Trevor is reasoning about a task in which there are two images of a ladder leaning against a wall. The ladder has moved in the two images to where the vertical distance the top of the ladder is up the wall has doubled, the length of the ladder itself has not changed, and the horizontal distance from the base of the ladder to the wall on the ground has visibly decreased, but by no given relation. The task asks Trevor to determine how the slope has changed between the two images.

\section{Excerpt 1: Session 1, November 16, August 3, 2017}

R: You know that the values of the ladder are changing, so think in terms of what you do know. $R$ : You do know the rise is changing, how is the slope changing? Is the slope doubling?

T: The rise is doubling... so that is probably how I know that it [the slope] is not less than twice what it was, because the rise is automatically doubling. The length is decreasing, so I know that it can't be exactly twice what it was, and that may be what I did, I may have done that over there as a close approximation on this pen it is closer to $2 / 3$ however that is irrelevant if the number is large enough. So I just took a close enough approximation to tell that the slope is more than doubling... If 3, if instead this had been something where the answer was closer to 2, like let's say I had ended up with a 2.2 answer, what I then would have done was tried to get a more accurate measurement somehow. Essentially I would have created a makeshift ruler and then used that to get a more accurate measurement and if I ended up with 1.9 I'd know it's a little bit less than twice what it was and if I ended up with two I would have reorganized that.

This method of reasoning is one of many to show how Trevor examines graphical and other visual objects. This excerpt was first coded in reference to the context of the task. In this case the presented task had a visual component of two figures of a ladder leaning against a wall. The graphical nature of the visuals were not necessarily obvious, as it was supposed to depict a ladder leaning against a wall, but also had arrows at the ends of the horizontal portion, the floor, and vertical portion, the wall. These two connected perpendicular rays resembled the second quadrant of a cartesian graph, and the ladder a line, which led it to be coded as a graphical in the context. The context of this problem was also coded as linear and trigonometric. It is linear in the 
sense that graphically the ladder forms a linear relationship with two different slopes in each image, and it is trigonometric as the relationship between the height of the ladder against the wall and the distance of its base from the wall along the floor could be related through trigonometry by the student, although that is not the case here.

These codes are necessary to examine Trevor's static or emergent shape thinking, as without a visual graph or other depiction static and emergent shape thinking are not applicable. For the activity Trevor was coded as static shape thinking as opposed to emergent shape thinking. This is because Trevor used his pen to physically measure how the base length was changing between images. Trevor was not attributing the change in the quantities of length and height to some relationship, but instead viewed the graph as a physical object with measurements that are used to solve the task. While solving the task, Trevor held his pen up to the length of the first graph, and compared it to the length of the second graph. This is where he got the approximation of it being $2 / 3$ the length. From there he had already calculated the approximate differences in the slope in the second as 3 times the first image based on this measurement. He discusses how he knows that this indicates the slope is more than doubling, and how if the approximation had led to a slope closer to doubling he would "get a more accurate measurement" by making "a makeshift ruler". This shows how reliant Trevor's view of the graph is on its physical properties and is why it was coded as static shape thinking.

When considering Trevor's process or action view of the function it is important to first consider if his shape thinking implied or references either of these. In Oehrtman et al. (2008) the there is an example relating the action view of a function to the behavior of treating the graph as a "geometric figure", which is what Trevor has done here with his static shape thinking. On top 
of the graphical action view of the function, it is also important to determine any other contexts which Trevor is viewing the problem through an action view. Trevor was also coded for an action view of the function when considering his view of the problem as a whole. While there was an underlying trigonometric function in the task, Trevor only considered the points shown by the two images. He did not apply a thought process that allowed for a continuum of images of angles changing as with the ladder being pushed up the wall, but instead focused on the two static images. From here it can once again be seen that Trevor is using an action view where the task is perceived as two slopes defined by two images as opposed to a continuum of changing angles and changing slopes.

This leads to interpreting how to code Trevor's covariational reasoning. This task was an example where Trevor's behaviors indicating covariational reasoning often seemed to be overridden by his static shape thinking and action view of functions. The covariational reasoning here is also complex due to the layers of quantities being considered for the covariation. The first instance where Trevor is showing covariational reasoning is between the quantities of "rise" and slope. Here Trevor is in the MA2 or MA3 range of covariational reasoning. His MA2 level can be shown by him recognizing that the slope more than doubles, but this is possibly leading to MA3. The next part creates a deeper understanding of where this concept of covariation came from, as Trevor adds the connection to the height change affecting the length change. This is clearly done at the MA2 level as the length is described as decreasing.

While Trevor measures the length and uses this to estimate the difference in slopes between the two images, this does not necessarily imply MA3 covariational reasoning. Trevor can compute rise over run as an applied action without considering the changing quantities. 
Furthermore, if his static shape thinking and action view of functions would have found a difference between the slopes as 1.9 times as much then this would indicate to him that the slope would be "a little bit less than twice what it was". This indicates that Trevor's reasoning earlier as the slope being "not less than twice what it was" could be overridden if presented with the opportunity. Thus, the behaviors of MA3 level reasoning (or higher) did not fit with the other coding of action view of functions or static shape thinking. Given this, the excerpt was coded at the MA2 level of covariational reasoning.

\section{Results}

Throughout the teaching experiment sessions, it was shown to be difficult for Trevor to provide meaningful description of rates of change of a function when the function presented had continuous change in the rate of change. Trevor generally portrayed actions consistent with MA3 and MA4 levels of covariational reasoning, reasoning at these levels in over half the examined segments. He did not ever clearly behave in a manner consistent with the MA5 level of covariational reasoning. These difficulties could be observed when he was presented with tasks where there was continuous change in the rate of change. While he was occasionally able to provide behaviors that indicated covariational reasoning at the MA5 level, he also often displayed use of pseudo-analytical behaviors alongside his reasoning.

In this paper Trevor's pseudo-analytical reasoning is associated with the two primary categories of static shape thinking and action view of a function. This is similar to the findings of second semester calculus students in previous research (Carlson et. al. 2002), where the student could exhibit behaviors consistent with MA5, yet their rationale relied on "memorized facts" and 
therefore the reasoning was classified as pseudo-analytic. When examining Trevor's difficulties in providing rationale for his reasoning that could be indicative of level 5 covariational reasoning it was clear that these types of pseudo-analytic behaviors were presented. For this paper the pseudo-analytic behaviors Trevor exhibited in solving various tasks can be more clearly categorized.

As will be shown in the following excerpts Trevor's solution of tasks has 3 main influences that seemed to affect his covariational reasoning and pseudo-analytic behaviors. The first two factors relied on Trevor's perceptions of various representations of the task. The representations of the task often did not affect Trevor's covariational reasoning directly, but instead influenced which pseudo-analytic behavior he applied instead of his covariational reasoning. Trevor often showed signs of static shape thinking (Moore \& Thompson, 2015) when reasoning about functions in graphical contexts. In such tasks Trevor often used physical properties, such as length and orientation. More directly, this type of shape thinking related to Trevor's covariational reasoning when he used physical properties of graphs instead of describing the relationships between the quantities. Instances like this include his use of the tangent line, his persistent use of "rise over run" even when the rise and run of the graph are not the two quantities examined, and his description of steepness.

While the graphical representation elicits static shape thinking, often Trevor transfers the graph into a tabular or algebraic representation himself. Once Trevor has an algebraic, or especially tabular, representation his action view of functions becomes more clear. In the tasks Trevor has made, or received, a table of values or an algebraic equation, he will calculate specific points and use them to find various solutions. This strategy is primarily effective for 
Trevor in solving the tasks, except when the task requires MA5 covariational reasoning. Given his action view of tabular and algebraic functions he can frequently find slopes over unit increments of change, and find patterns between those slopes, but it is difficult for him to then describe or use the sections of the original functions between the chosen increment, leaving him stuck at a maximum of MA4.

Lastly Trevor's understanding of the derivative and integral are revealing to how he reasons covariationally. Since each of these functions have MA5 covariational reasoning as an underlying aspect of them through continuity and change in change, it is more clear to see his missing MA5 in these instances. From there it is also useful to examine where his action view of functions, static shape thinking, or other pseudo-analytical behaviors appear and how they are, and are not effective for him across tasks involving these calculus functions. Given the usefulness of imagining continuous change in calculus courses, examining how Trevor uses his MA4 reasoning with these calculus functions reveals how action views of functions and static graph thinking can limit his ability to solve tasks.

\section{Covariational Reasoning below MA5}

This section explores Trevor's varying degrees of success when solving tasks involving linear and quadratic functions while applying covariational reasoning below MA5 combined with pseudo-analytical thinking.

\section{Linear functions and MA4.}

The first excerpt focuses on Trevor's solution of a task asking him to use a graph in order to find a formula for time as a function of volume. This problem had been initially solved by 
Trevor in a test like environment, and now some of his answers were being reviewed. Before the start of this excerpt Trevor had confirmed how he obtained his previous answer by using rise over run, and had also found another way of representing the relationship, the inverse. The answer of $t=\frac{v}{2}$ is Trevor's initial answer and the inverse of the correct answer $v=2 t$.

\section{Excerpt 2: Session 1, August 3, 2017}

$R$ : So what's the rate of change in $t=\frac{v}{2}$ ?

$T$ : The rate of change is time equals $1 / 2$ the volume, the change in volume

$R$ : So the change in... Can you say it in terms of how time is changing,? Like you said earlier with $1 / 2$ units and units, for every...

T: For every gallon increase, time is... for every unit increase in volume you have $1 / 2$ unit increase of time

$R:$ Is that the same as what you explained in $v=2 t$ ?

$T$ : Its... let's see here, it's not the inverse, what's that phrase... It expresses the same change it just, in this case its $t$ with respect to volume, or is it volume with respect to $t$, I get that confused, so...

$R$ : So its a constant rate of change...

$T$ : Yes, it's a constant rate of change in this case... Oh I see, it's a function of volume. As a function of volume [phrase from original problem]

R: You're looking at the instructions?

T: Yes

R: Why did that suddenly come into your mind?

T: I think, see my problem is... so this would be t as a function of volume, when I put $v=2 t$ I put down as... rise over run which, this isn't actually asking for rise over run, it's asking what.. how t changes with respect to volume

$R$ : So you think the answer you chose is incorrect?

T: It may be, this is where I run into problems with the wording of things.

Here Trevor is showing how his initial methods of solving the problem conflict with some of his understandings of covariational reasoning. In his first response to the researchers question Trevor examines the algebraic representation of the answer $t=\frac{v}{2}$, where he manages initially reason about the variation of a singular quantity, change in volume. There is no explicit reference to change in time however, so it is difficult to determine if he is using covariational 
reasoning to solve the problem, or some other method. Trevor repeatedly phrases statements in this manner, with one quantity in terms of change in the second quantity, with no clear notion of the first quantity being thought of as changing simultaneously. This is especially difficult to examine in this context, as time is one of the quantities covarying and it can have the connotation as inherently being continuous and changing. Given an assumed change in time it is possible Trevor is initially reasoning covariationally at the MA3, MA4 or MA5 level. Alternatively Trevor may be examining the original function through the lens of an action view, in which case he only needed to calculate the slope through the action of rise over run, and add in the algebraic step of "switch and solve" (Oehrtman et al., 2008) to find the inverse. After his initial response the researcher guides Trevor to a style of sentence he had used earlier in his description of his answer, $v=2 t$, but with reference to the new equation, $t=\frac{v}{2}$, being examined.

In Trevor's response to this new prompt he is able to more clearly express a MA4 level of covariational reasoning, expressing how time increases in reference to how volume increases, each by unit increments. It is important to make clear that although Trevor is at the MA4 level of covariational reasoning, it is not a given that his earlier thought process had been considering covariation at this level. Given the nature of Trevor's words in response to the guidance, while the examined section is coded as MA4 here, he could also be reasoning at the MA3 or MA5 levels. This is because it is often more difficult to determine the exact level of covariational reasoning employed by the student when the context is linear, as they tend to blend together more than in non-linear contexts.

In this problem Trevor did initially only examine the slope between two points. However, he may have determined that the slope was constant by using shape thinking seeing that the 
graphs steepness does not change from the slope he looked at, which would likely leave his covariational reasoning at MA3. Alternatively he could have also determined that the unit increase is infinitesimal and constant throughout the entire function and that these unit changes don't have meaning to specific increments, but instead indicate a continuous relationship, which could be reasoning covariationally at the MA5 level. Given his specific phrasing however, it appears Trevor's covariational reasoning is closest to MA4 here. An additional concept to note is that Trevor does not particularly need to have a MA4 or MA5 level of covariational reasoning to understand the task and express his understanding fully. Trevor has the ability to answer the task here at an MA4, or even MA3, level of covariational reasoning with the use of some common pseudo-analytical processes, such as finding rise over run, and using the switch and solve for the inverse.

In this section Trevor also struggles with terminology, he states that "it [answer $t=\frac{v}{2}$ ] expresses the same change [as answer $v=2 t$ ]", but is not sure if that is the inverse. He also struggles determining how the phrase "with respect to" works in functions and the relationships between the input and output. This creates a distinction between his solution of the task and his covariational reasoning, as he is unsure of whether $t=\frac{v}{2}$ or $v=2 t$ is the correct answer, yet it is not his image of quantities changing that limits this, but instead his understanding of specific phrases from the problem.

On top of this his use of "same change" is unclear, but seems to be expressing that he understands that the way the quantities covary does not change, even if the input and output relationship is changed. If this is the case Trevor is displaying a process view of the inverse in this section, even if he earlier solved for it using the switch and solve method. This indication 
toward a process view is rare for Trevor, and even here it is hard to be certain. Also in this section, Trevor shows that upon closer examination of the problem he is no longer sure if his initial answer is correct, and adjusts to the fact that a calculation of "rise over run" may have been an incorrect method to solve this task. This is an instance where Trevor examines a problem initially with pseudo-analytical thinking, that rise over run expresses a the input and output relationship not matter the orientation of the graph, but then later through additional work realizes his initial method of solving the task may have been inappropriate for this context. Despite this being the case, Trevor does not necessarily apply this new understanding of where not to apply the method of rise over run in future cases. He continues to use rise over run in other tasks without much regard as to whether or not it applies.

Overall this excerpt shows Trevor's ability to use action views of functions and static shape thinking to supplement his MA4 covariational reasoning. With terminology assistance these methods allow for him to identify the correct answer. Here Trevor's methods and behaviors, such as finding rise over run, may have initially created incorrect solutions to the problem but were later able to be used to correctly solve the task. This example shows how these types of pseudo-analytical behaviors can be reinforced, as they promote solutions to the problem.

\section{Quadratic Functions and lack of MA5.}

The next excerpt examines a case where Trevor is now working with the quadratic function $y=x^{2}$, and discussing how he views its concavity. This is a case in which Trevor's reasoning reflects many of the behaviors discussed in Excerpt 1, but given the non-linear nature of the function it is easier to determine where that reasoning can provide barriers for him. 


\section{Excerpt 3: Session 2, August 10, 2017}

T: When we are speaking of concave up we are talking about the direction both of these lines are pointing...

$R$ : [Covers negative $x$ values] Is this part of the graph concave up or concave down and why?

T: Concave up because it is the overall direction... the overall direction that the graph is pointing towards... y is going to continue going up, it will never go down... or y is continually increasing. $Y$ is always going to be a positive number and it's always going to increase as $x$ increases

$R$ : What about this one? [covers positive $x$ values]

T: It's still concave up...

R: Why?

T: Because the concave... the same reason it was for this direction [covers negative $x$ values] it's just a different half of the graph.

R: On this side you said y is always going to be increasing, so why is it concave up? Is y always increasing?

T: Yes, $y$ is always increasing, in this case it doesn't matter that $x$ is negative because a negative multiplied by a negative is going to be a positive.

The first notable part of this section is that Trevor correctly identifies concavity, which reflects behavior of MA5 covariational reasoning. Using the MA5 behaviors of the framework, Trevor correctly identifies the direction of the concavity of the function and is also thinking about "y continually increasing". However, more than a mere identification of concave up or down is required, an ability to identify how the concave up graph connects to the rate of change increasing is required, and without this is labelled as pseudo-analytical thinking (Carlson et al., 2002). In this section Trevor uses the phrases, "y is continually increasing" and "it's [y] always going to increase as x increases". These phrases together next to each other imply Trevor is thinking of a continuous increase in $y$ and some level of dependence on $x$, which on its own this is only indicative of MA2 thinking. If Trevor were to identify the change in y, or the rate of change, to be continually increasing then it would more closely match MA5. Additionally, Trevor describes concave up as the direction both the lines are pointing, which indicates that his 
initial assessment of the concavity of the function is heavily reliant on visual cues and geometric shapes of the graph, which is static shape thinking. This does not indicate MA5 level of covariational reasoning, but instead indicates that Trevor has memorized what concave up means in terms of graphical shape, and is instead a kind of the pseudo-analytic thinking.

Following this part of the task, Trevor is presented with a new perspective of the graph, where now the positive $\mathrm{x}$ values are covered instead of the negative. Given either of Trevor's earlier explanations of why the graph is concave up this graph would not be concave up, but he still concludes that it is concave up. This also relates to how Trevor's earlier statements are likely not indicating MA5 covariational reasoning, as he is applying the same reasoning in places it would be false. Here Trevor's reasoning seems to indicate either incorrect MA2 level of covariational reasoning, or none at all. For the MA2 level he describes the direction of the graph but since he believes it is the same explanation as earlier, the direction would be incorrect for $\mathrm{y}$. For no covariational reasoning, and instead pseudo-analytic thought, Trevor's discussion of direction and pointing indicates static shape thinking. Additionally some of his explanation relies on the orientation of the graph, as he uses terms such as going up instead of increasing. This is another instance where Trevor relies on this orientation, as he did earlier with rise over run in Excerpt 1.

Another reason it is difficult to determine the covariational reasoning in this section is that Trevor rarely refers to the variation of more than one quantity explicitly. This was discussed in Excerpt 1 when Trevor was discussing time and change in volume, and here Trevor is not connecting change in $y$ to change in $x$. He is instead explaining that $x$ being negative doesn't matter in his explanation. Trevor may imply the change in $x$, as $y$ is continually increasing, or 
going up, but only at the end of describing the graph with the negative $x$ values covered is $y$ described as "increasing while $\mathrm{x}$ increases", but it is still unclear as to how $y$ is increasing as $x$ increases. Part of the examination of Trevor's work relies on determining if he is actually describing the situation at hand, or just using descriptions that are accurate but not directly addressing the issue. Looking at this, all the justification presented by Trevor could just as easily describe a linear function, which at an MA5 level of covariational reasoning should have a different meaning then a quadratic function.

Since Trevor applies the same reasoning for negative inputs, (where his statements are false) as positive inputs, it is hard to presume he is reasoning covariationally at higher levels. Instead there are some aspects of pseudo-analytic thinking at play. For his covariational reasoning to be correct, the behavior would have to be examined under the assumption that he is referring to the rate of change of $y$ when he discusses $y$. However, if that is the case and Trevor is reasoning about the concavity as the change in rate of change, he would have likely been able to distinguish $y$ from change in $y$.

Alternatively Trevor could actually just be considering that the whole graph as being concave up based on his static shape thinking, and this is why he now has difficulties explaining why the negative half of the graph is concave up. This line of thought is supported by Trevor stating $\mathrm{y}$ is still increasing, and saying “it doesn't matter that $\mathrm{x}$ is negative because a negative multiplied by a negative is a positive". While there is no complete clarity as to what Trevor means by this in the context, it is clear that he is not thinking about changes in $y$ and changes in $x$ at this point, as $y$ is changing negatively in reference to positive changes in $x$, and vice versa. Trevor could still be reasoning about rate of change of $y$ and that it is changing in a positive 
fashion, but there is not indication of this here. Also, the phrasing of the later part of the excerpt seems like it could support that he is not considering a varying quantity of $x$ at all. As earlier in the excerpt he considers how $y$ is always increasing with reference to $x$, and then later $y$ is just always increasing, with no reference to $x$ (possibly because this would be false in the context).

This excerpt clarifies how a student can reason with uncertain levels of covariational reasoning, and how a student can leverage understandings of shape thinking in order to determine what concavity means. Additionally this excerpt helps exemplify that when examining covariational reasoning there can be difficulties gauging what levels are in use based on contextual factors. This section is likely an indication of Trevor using static shape thinking and other memorized facts instead of an image of covariation. Despite leveraging a definition for concavity, Trevor's was not able to consistently apply this level of reasoning to the task as its representation was changed and his shape thinking and initial MA2 level of covariational reasoning left missing elements for Trevor's explanations of the task.

\section{Quadratic Functions and MA4.}

The following excerpt reveals Trevor's thinking based on representations further by examining his use of tables in problems that include quadratic functions. The original problem asks for the area of a circle in terms of time, given a function of the radius of the circle in terms of time. Trevor has created a table of values by solving for the area at 1 second intervals, taking the difference in these areas, and taking the difference in those differences. Here he is attempting to explain what result he has found by creating this table of values. His use of integer increments and differences between these specifically chosen values appear to guide his covariational 
reasoning. Additionally, before examining this section it is important to note that the original question did not necessarily require any covariation, as it and instead focuses on composition of functions and a process view of functions.
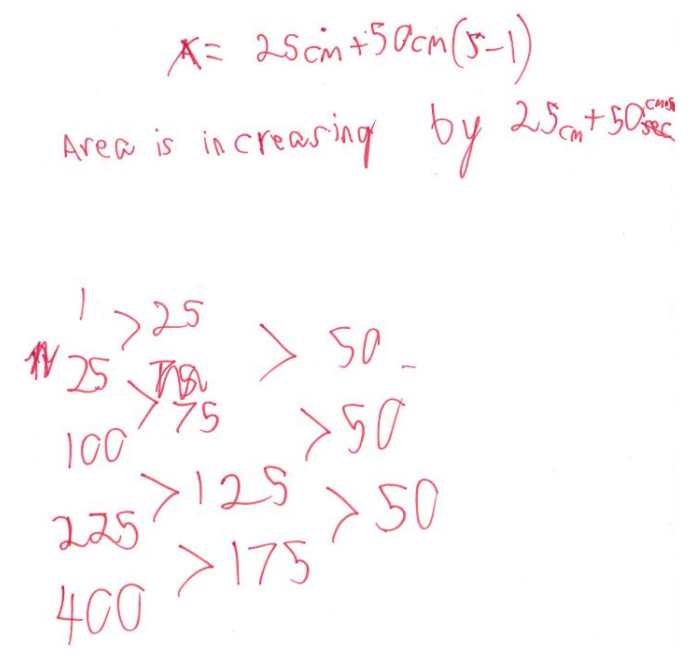

Figure 2. Table of values and equations to solve for the area of the ripple over time. Trevor's work on the task including calculated areas, first and second differences of those areas, and linear equations to express the relationships found in the task.

\section{Excerpt 4: Session 1, August 3, 2017}

T: So I have here is the area is increasing by 50 each time... or it's the previous amount plus $50 \ldots$

$R$ : Say that one more time, maybe write out what you are saying...

T: [writes] So the difference between that would be 25 [writes] Times 50 per second

$R$ : So you wrote area is increasing by 25 , what's that?

T: $25 \mathrm{~cm}$ plus $50 \mathrm{~cm}$ per second... so what we have here is the initial increase would have been 25

$R:$ So is it increasing at a constant rate?

T: [thinks] The area would be increasing at a constant rate... actually [thinks some more]... Yeah the area is increasing at a constant rate.

$R$ : What is the constant rate it is increasing?

$T:$ It is $50 \mathrm{~cm}$ per second

R: So after 1 second it goes up 50 and after 2 seconds it goes up another 50, and after 3 seconds... The area?

T: Yeah, so the area, that's what I'm trying to... So it's not going up... This is when I run into problems getting what I'm thinking in my head on paper...

$R$ : Is the way this is changing the same as the earlier problem with the tand the $v$, where $t(v)=\frac{1}{2} v$

T: It's changing differently, each... In this case it's a... Actually that's wrong... again. So there is a difference, in the $v$ divided by 2 we had a linear progression and this isn't a linear increase in area. 
Important to note is that within the creation of this table, Trevor has managed to compose the functions at times on unit intervals. This means Trevor has solved the task based on an action view of composition of functions, but does not seem to recognize how this is the solution to the task, and creates a table of values and differences between them to try and find some kind of equation. This may be reflecting Trevor's need to find rise over run in order to create an equation for a contextual problem, or some other kind of memorized technique that is not necessary and is detrimental to solving, the task.

This section displays two important features commonly shown by Trevor related to his covariational reasoning. The first is related to the Excerpt 2, where Trevor is using MA4 levels of covariational reasoning, and has a difficult time differentiating linear functions from other power functions, as he can repeat the MA4 covariational reasoning until there is a linear relationship. The second aspect of Trevor's reasoning it displays is his use of algebra in a tabular context, and the difficulties that arise from it later on.

Here Trevor seems to be engaging in a MA4 levels of covariational reasoning to examine a quadratic function. He is able to determine the secant lines on unit intervals correctly, and relate them to each other, as increasing by 50 , but his covariational reasoning, and/or language, suffers and leaves him making inaccurate statements. The primary inaccuracy is the fact that Trevor is unable to appropriately determine what quantities are actually covarying at a multiplicative rate of 50. This leads to confusion for Trevor as to which pieces of his work refer to the area, and which refer to a rate of change of the area.

When Trevor created a table and found differences between them until he reach a constant difference, this implied to him that there was a linear relation present. He had found that 
something had a linear relation of increasing by 50 per second, but he either could not determine what was changing at 50 per second, or he attributed that to the area, which is inaccurate. In this case the table enforced a maximum of MA4 level of covariational reasoning by creating a lack of reference to points in between, or outside of, the unit chunks. Additionally, despite the construction of rates of change over unit intervals and finding patterns in the values between them, Trevor has not behaved consistently with MA1 reasoning for the change in area compared to time. This would mean that Trevor's level of covariational reasoning could be missing altogether in this instance, as he has not identified the appropriate quantities covarying for the numbers he is applying.

This relates to the other large factor presented here that is leading to Trevor's confusion, which is the tabular representation he is employing. The table is left without any labels of time, area, or average rates of change of area, leaving Trevor with a collection of numbers and no context as to what they mean or how they relate. This not only leaves Trevor with issues related to identifying the appropriate two quantities of a function, or a covarying relationship, but also leaves him with difficulties matching up the units of measurement in his explanation. The answer given is that area, which in this task the units would be $\mathrm{cm}^{2}$, is made equal to the expression $25 \mathrm{~cm}+50 \mathrm{~cm}$ per second, a unit of length. Even when asked about the area increasing at a constant rate (which it isn't), Trevor considers it and thinks that it is, possibly because his unlabelled work doesn't give him the ability to review what quantities are covarying in what way. Only when he is guided step by step, "so you are saying the area is changing by 50 each time" does Trevor seems to realize that his equation might be wrong in context, and when it is compared to the earlier linear relationship Trevor accepts that it is not linear in reference to area 
and instead something else. He even gets close to saying something that would give him a more clear MA4, or even MA5, level of covariational reasoning with the correct input and output for the numbers being used, but trails off, not finishing what is "changing differently each...".

Lastly, this section partially supports the assessment of the concavity work as shape thinking, as in later in solving this task Trevor is having difficulties addressing what is changing positively in reference to $\mathrm{x}$, which closely resembles that thought process from Excerpt 2 . This section also displays a difficulty with interpreting Trevor's covariational reasoning. $\mathrm{He}$ recognizes MA1 and MA2 levels of covariational reasoning of relationships and directions, but the MA3 and MA4 levels are vague, and he has self-admitted difficulties putting his thoughts into words. It can be observed that the actions taking place imply that there are is some understanding of average rates of change over unit intervals, but he is unable to correctly identify which quantities are changing in reference to each other and relate that to those numbers. Thus, his reasoning had the form of pseudo-analytical thinking related to an action view of functions as opposed MA4 covariational reasoning.

\section{MA4 Covariational Reasoning and Calculus concepts}

This section explores how Trevor's use of MA4 covariational reasoning interacts with concepts found in calculus.

\section{The derivative and MA4.}

For the first excerpt examining Trevor's reasoning of the derivative it is being examined in reference to the concepts of covariational reasoning and action views of functions. This excerpt it is a continuation of the task and problems Trevor had been working on in Excerpt 2. 
Here Trevor is continuing his work with the concavity of the function $y=x^{2}$, and doing so in a guided manner that initially followed how he worked with from the task of Excerpt 3. Here the student is first looking back at the work he has done for the problem, which was creating secant lines and average rates of change of the function over unit increments, and now this is being transitioned into work on derivatives and concavity.

Excerpt 5: Session 2, August 10, 2017

$R:$ What was the original pattern, an average rate of change over a unit interval?

T: I noticed that for... every increasing of 1 in $x$ the average rate of change increased by 2

$R$ : Does that pattern hold for every $x$, or any $x$ I pick, or only some of xs?

T: I believe it would hold for every $x$, but I don't have any way to prove it, but I believe it would hold for every value of $x$

$R$ : How would you prove that?

T: I honestly don't know off the top of my head...

$R$ : What did you write down?

T: The average rate of change increases by 2 for each increase of 1 on the domain

$R$ : I now want you to do a little calculus, so you have a polynomial function $y=x^{2}$, what is its derivative?

T: The first derivative of $f(x)=x^{2}$ is $2 x$

$R$ : What does that mean in terms of the rate of change?

T: That's the rate of change of the function so [points at $f^{\prime}(x)=2 x$ ], what we end up with is for any value of $x$ we get the rate of change on that point. That would be the tangent line though, not the secant.

R: Give me an example

T: [Writes out some examples]

$R:$ So what does that mean

T: That tells me the rate of change at a specific point in time...

$R: O k$, now what is the second derivative of the original function?

$T$ : It's going to be 2

$R:$ What does that mean?

T: [pause] That's the constant... that tells us... how much the function of $x$ increases for each increase in $x$. What that tells us is... That's the derivative of a derivative, that's essentially the tangent line of the tangent line.

$R$ : Can you tell me what it means in terms of the concavity of the function?

T: [Pause] In terms of the concavity of the function, because the... second derivative is positive that tells me the concavity is also going to be positive or upward facing. So it is concave up. $R$ : Can you tell me what it means in terms of the changes in the slopes of the tangent line of the original curve?

T: ... That tells me that's the rate by which... I'm not certain rates the right word, but that's the 
rate by which the tangent line inc[creases]... the average rate at which the tangent line increases...That tells me for each increase in $x$... or each increase of 1 in $x$, the rate of change of the tangent line is going to increase by 2.

$R$ : How does that fit with your earlier work with secant lines? Maybe particularly what you wrote up here?

T: So that fits very well with the average rates of change, and it actually looks like the tangent line is just a shifted secant line...

When moving on to these problems that directly involve calculus concepts, Trevor still uses much of the pseudo-analytical thoughts about the covariation through action views of the function and static shape thinking. Importantly, given these methods for problem solving, Trevor still does not achieve clear MA5 levels of covariational reasoning. In this excerpt Trevor's reliance on graphical visuals and their meanings come into play when considering what the student understands about concavity and tangent and secant lines. Additionally, Trevor's use of MA4 level of covariational reasoning without displaying clear MA5 level is often more clear to detect when Trevor is using the derivative, as the derivative is a tool that shows the continuous change of the rate of change. As described in the analysis below, when Trevor uses the function of the derivative through an action view, his behaviors contradict his thinking about the derivative as a continuous function.

Trevor initially has difficulty finding how the patterns of the secant lines apply. He believes it would hold for every $\mathrm{x}$, but despite having access to the derivative, he states he doesn't know how to prove the pattern he noticed. The researcher then guides Trevor to examine the average rate of change in reference to the derivative, by having the student calculate the derivative. The algebraic calculation is done quickly and correctly, but when Trevor must explain how the derivative relates to the rate of change there is some evidence that Trevor may be relying on pseudo-analytical thinking to support his answer. This is an opportune moment 
where Trevor could apply MA5 reasoning. It initially seems like he does, as he describes the derivative as the rate of change of the function, and even states that for any value of $\mathrm{x}$ that it is the rate of change on that point.

Trevor makes it seem possible that his reasoning may not be MA5 when he goes further in his description. He uses the two different terms "any value of $x$ " and "on that point". The first generally indicates an understanding of the derivative as a function as a process, where there is a continuum of $\mathrm{x}$ values as inputs, and a continuum of derivatives of the function as outputs. The second indicates that the derivative may be thought of through an action view and that there is a choice of an $\mathrm{x}$, and an output of a slope at that specific point. The latter is furthered by his description of the derivative being "the tangent line" and not the secant. The use of "the" combined with "tangent line" (not tangent lines) indicates a lack of thought of more than one tangent line at a time. This indicates that he may not be reasoning at MA5, as he is not recognizing the continuity of the change in one quantity with another.

When Trevor is asked to give examples, he plugs some integers into his function, and he does recognize that the left side is the negative equivalent of the right side. He then continues with additional language that indicates notions of singular points, now referring to a rate of change, but still at a "specific point in time". This type of action view of the derivative closely supports a maximum of MA4 reasoning, especially when paired with how the $\mathrm{x}$ values to evaluate through actions are often integers.

When asked to give the second derivative the initial algebraic calculation is similarly quick to the first derivative, and his interpretation is still indicative of MA4. He states that the function of $\mathrm{x}$ increases for each increase in $\mathrm{x}$, where according to the notation on his paper the 
function of $\mathrm{x}$ is the derivative of the function $y=x^{2}$. This sounds almost like MA5 reasoning initially, but there are a few instances where he indicates that he is more closely reasoning at the MA4 level. One piece of support for his MA4 level is when he says that it is the change for "each" increase in $\mathrm{x}$, which seems to be more clearly referring to an exact interval, such as the average rate of change over a unit interval, as opposed to the word any which would indicate a more clear thought of continuous changes. Additionally he describes the second derivative as the derivative of the derivative, which while accurate describes no covariational reasoning, and also refers to it as the tangent of a tangent line. This line of thought is difficult to discern if Trevor is reasoning with any image of covariation.

Trevor's use of tangent line is also often a thought of the tangent line as a physical object, with steepness and other properties, more than a concept of rate of change of a function. When discussing the connection of second derivative to concavity, Trevor only manages to directly connect the fact that the positive second derivative indicates a concave up function, while also again referring to visuals of the graph itself. All of these factors indicate a lack of understanding of how the derivative and tangent line relate to the function, especially when there is a second derivative involved. Additionally it once again is closely related to how Trevor can use many memorized methods to determine and support concavity without displaying MA5 covariational reasoning.

Finally Trevor is asked to explain how the second derivative connects to the tangent lines of the original function. He is able to recognize it as as the average rate of change of the slopes of the tangent lines to the original function, which is incomplete, as the second derivative does not only relate to the average rates of change, but relates to continuous change in the rates of 
change. Here is another instance where Trevor uses MA4 reasoning in an instance where MA5 could be applied. This is shown more specifically when he describes how for each unit increment of $x$ the tangent line will increase by 2 . This shows Trevor's persistent use of the MA4 level of covariational reasoning on a variety of functions, including tangent lines. From here Trevor is trying to connect the derivative to the secant lines, and he makes an astute observation between the secant lines and the derivative. Trevor notices that each derivative he found matches some average rate of change, or he could find a tangent line shifted from a secant line. Trevor also manages to recognize that in this shifting of the secant line the tangent is somewhere halfway between the secant line, so there is some recognition of the existence of the derivative between two integer values on the function. This was an initially examined as certain evidence toward MA5 level of covariational reasoning, as Trevor is close to creating the mean value theorem. This recognition, however could have been created through many other methods without considering covariation. Additionally, recognition of a point in between two integers does not automatically override the evidence toward Trevor's action view of functions and static shape thinking that could still be taking place. This type of recognition of values between two integers will be examined further in the following examples as well, and in those cases seem to indicate that he is not reasoning at the MA5 level.

Here some important features of Trevor's covariational reasoning and understanding of the derivative are revealed. This excerpt supports some of the previous work, where Trevor may on the surface look to be displaying behaviors that indicate higher levels of covariational reasoning than are initially presented. The indications toward his lack of covariational reasoning in this excerpt once again are focused on his action view of functions, and how this relates to his 
understandings of the first and second derivatives. Additionally there is evidence of static shape thinking that helps him find the answer to the task, but not necessarily show a strong understanding of it.

\section{The derivative and shape thinking.}

This section focuses on Trevor's consideration of graphical representations and static shape thinking in the context of the derivative. Additionally, it provides insight into Trevor's reasoning about singular quantity variation, which may provide insight into his multiple quantity covariation.

\section{Excerpt 6: Session 4, November 30, 2017}

$R$ : What was delta $x$ representing?

T: The width given here, the change for a given length, so if each of these is 1, it's just the width of that, where as the derivative of $x$ would represent the instantaneous rate of change at an infinitesimally small point.

R: Now apply that to arc length...

T: Oh, it's just the tangent line given here..

$R$ : What is what, what is the delta $a$ and what is the da?

T: So the delta a would represent the change in output for a specific length of a. So if that represents an arc length it would be a secant line of the arc length, whereas the derivative of a would be a tangent line given.

$R$ : So when you have delta $x$, you think of that as part of a length, and so for delta a that represents part of...an arc length

T: A part of an arc length, where derivative of a gives me a specific point, and...

This section is important to examining Trevor's covariational reasoning related to the derivative, as it is examining how Trevor reasons about the term $\mathrm{dx}$, and how this transfers across contexts. First, when Trevor thinks of delta $\mathrm{x}$, he does think of some consistent increment of change in $\mathrm{x}$, but describes it as specifically a length, or the width along the $\mathrm{x}$ axis. The increment used is also changes by 1 , which reflects some of his natural tendencies from the previous examples. Additionally, instead of directly responding to the question of what dx 
means, Trevor chooses to insert the derivative of $x$, as the instantaneous rate of change at what is once again some specific point. Here Trevor could be mishearing the question, or assuming $\mathrm{dx}$ means the same thing as the derivative of $\mathrm{x}$. This also shows how similarly it could be possible for Trevor to use terms like rate of change without seeming to have two quantities in mind that are varying. This can be shown by him creating a derivative at a point when there is no explicit function whose derivative is being taken. Alternatively, he could be understanding that the derivative is its own function, and that any input has exactly one output, which could be appropriately represented by a point on a graph. While possible it is difficult to determine whether Trevor thinks of the derivative as a function itself. This instance also displays Trevor's use of singular language when referencing the derivative, supporting the earlier examinations of him viewing the derivative through an action view.

When he then applies this to a depiction of the unit circle and the arc length, the variable $a$, he applies his visual standards for both the derivative and the average rate of change as he would in other contexts. The difference is that in this representation, the lines he is drawing do not depict the relationships he is trying to relate, but instead $\sin (a)$ and $\cos (a)$. Here he seems to struggle to think of the change in arc length, delta a, as anything but a secant line of the unit circle, which would be the chord of the arc length, instead of the curved arc length itself. This could be that Trevor's static shape thinking as related to the change in a variable forces him to depict it as a straight line segment, with a linear distance.

Trevor's identification that the derivative would be represented by a tangent line reveals other contradictory aspects of his thinking. First, the slope of this tangent line of the unit circle is not necessarily going to be representative of the slope of the function at that angle, which Trevor 
does not grasp. Additionally in the context of the secant line, if the tangent line is still the instantaneous rate of change, then it would likely be that the secant line is still representative of the average rate of change. This conflicts with the description of the secant line as a length, or a change in a single quantity. No matter how he is viewing the secant line, there is some kind of misunderstanding of change and rates of change in this context. Also these reflect earlier examinations of Trevor's work, as not only is he continuing to use visual cues and shape thinking in his calculus work, but his views of delta a or $\mathrm{x}$ and da or $\mathrm{dx}$, reflect his use of MA4 in the use of delta $\mathrm{x}$, and the action view of the derivative function with da. Lastly, Trevor continues use of methods and words that indicate the derivative is being thought of as an action, only finding singular points and attempting to work from those individual points.

\section{The antiderivative and action views.}

This excerpt includes Trevor explicitly describing his view of the algebraic representation of the derivative as a "shortcut". This section includes a few components of Trevor's views of the integral as it relates to his action view of the function. Here he is working with $\int_{0}^{\pi} \sin (x) d x$

\section{Excerpt 7: Session 3, November 16, 2017}

$R:$ What does this tell you?

T: So,the first thing this tells me is I'm dealing with an antiderivative of sin [points at sin] and the d of $x$ [points at $d x$ ] tells me that its with respect to $x$ [points to $x$ ]. So thats the first portion of what it does [points to entire sinx dx], but it also tells me that I'm going to be, um, finding the difference between two points on that antiderivative [points at 0 and $\pi$ back and forth], so in this case I'm going to be subtracting [points at $\pi$ ] um, this would be I believe -cos $(\pi)$, or i'm sorry, I'm going to be subtracting - $\cos (0)$ from $-\cos (\pi)$, and so what this process essentially tells me exactly what I'm going to be doing with the problem.

This excerpt is an important feature to how Trevor considers covariation in the integral 
function given the algebraic representation. The first aspect is his view of " $\mathrm{d}$ of $\mathrm{x}$ ", in which it tells him what variable the function is "with respect to". Here dx is just telling him what variable to refer to in his action view, and is not viewed as a change in $\mathrm{x}$. This shows how he is not necessarily thinking of sine and dx multiplicatively like a Riemann sum with a height at a point sine and an infinitesimal width of $\mathrm{dx}$. Instead he sees there being one function, sine, and a symbol, $d$, where the letter following the $d$ tells him what variable to use to algebraically calculate the antiderivative. This seems to in general indicate a lack of a multiplicative relationship in the quantity $f(x) d x$, which leads to a lack of thought of accumulation and a lack of thought of covariation.

He continues his action view of the entire function by describing the bounds and method used to solve the integral. Here he describes it as a difference, and how he will use subtraction. This indicates a lack of continuous covariation of a multiplicative relationship, and instead a procedural list of actions to use to solve the problem. Each of these aspects leads to an action view of the integral, which then leads to an upper limit of MA4 covariational reasoning in reference to the integral as a function. Additionally the confusion around dx and lack of a multiplicative meaning create a situation where Trevor has an unclear notion of the input, or possibly inputs in his mind, of the integral. Without a clear input and output relation this would cause difficulties with MA1 covariational reasoning, which would be required to achieve the higher levels of covariational reasoning.

In another section of his work, when solving for the same integral with an upper bound of $\mathrm{y}$, he describes the upper bound as an "unknown constant" and thinks of what is being found as an area. The use of the phrase "unknown constant" as an alternative for a variable is indicative of 
an action view, as Trevor can then think of $y$ as a constant, and once that constant becomes known it can be plugged into this action view. This is instead of viewing y as a variable where it is a process where changing the y accumulates more or less area, or something else, through the multiplicative relationship.

It seems that Trevor has a lack of an image of a process view of the integral function, leading him to think of the algebra through actions applied to numbers. Additionally it creates a lack of a multiplicative relationship being imagined, possibly resulting in a static shape thinking view of the integral as some graphical area, as opposed to accumulation of quantities. This relates to Trevor's covariational reasoning, as accumulation is a process of imagining the multiplicative relationship of these quantities, and we see Trevor fall back on some other methods to describe the function.

\section{The antiderivative and shape thinking.}

This excerpt shows an alternative view Trevor has to the integral function, through the graphical representation. Additionally it reveals his static shape thinking of the integral through this context, and how he uses the physical properties of the graph.

\section{Excerpt 8: Session 3, November 16, 2017}

$R$ : So here is a graph. So there is a function, what does that say there?

T: It's blasphemy is what it is

D: It's flipping it

T: The function of $y$ equals the integral of zero to $y$ of $\sin$ of $x d$ of $x$

$D$ : Now we are flipping it on its side, as if the $y$ is $x \ldots$

$R$ : The way it's being graphed is wrong, one second [works on app]

T: That's why I said it's blasphemy, it is not a function a function may not

D: That function is equivalent to that area

T: No, no, because you can't have more than one point, on any function you cannot have more than one point on the vertical axis. 
D: It reminds me of the fundamental theorem of calculus part 2, like where the its switching the values of the argument and the bounds.

T: It's just the cosine function shifted up

D: Negative cosine

T: It's just the negative cosine function shifted up

R: By how much?

T: It's shifted up by negative one

$R$ : It's shifted up by negative one?

D: By one

T: [Clearly sees mistake]

$R$ : does shifting up by one make sense?

T: Yes, because what we're looking for is the area of sin and the minimum area of sin [creates bounds with hands] would be zero because we have, [moves right hand to left] of we have the origin at zero and then because sin is a wave function [draws sin function in the air, starting by going up from origin, and then down below, and then back up to starting point of y axis] if you subtract one wave [points at imaginary area of sin from $\pi$ to $2 \pi$ ] from the other wave [points at imaginary area of sin from 0 to $\pi$ ] because it's negative area [points at imaginary areas back and forth as if to show cancellation] you end up with zero [points at the middle point-ish $(\pi, 0)$ ] so there's your minimum [points at $(\pi, 0)$ on graph of 1-cosx] and then, as for two that is just the maximum area of the total of one wave...

Right away we have an instance of static shape thinking in reference to the integral when the graph is shown. The graphing program uses y as the independent axis which Trevor does not seem to approve of, describing it as blasphemy and calling it not a function. This is the type of static shape thinking is exactly like that is used in (Moore \& Thompson, 2015). The issue with this level of static shape thinking is that Trevor believes that the function, which algebraically is defined as a function, is suddenly not a function because it is graphed in a different orientation, and Trevor's definition of a function based on points on a vertical axis is what he uses to assess it. This also shows how he is not using higher levels of covariational reasoning in this instance, as he is not attending to input output relations, but merely how the graph looks.

When the graph is reoriented in a more natural manner for Trevor he begins to be able to pick it apart using his covariational reasoning. While he is initially struggling with what kind of 
trigonometric function it is and how that function is shifted, this is most likely just due to him saying his thoughts out loud as he thinks them, as he goes on to give a detailed description. His detailed description as to why it makes sense that the graph is a negative cosine shifted up 1 is more clear than a lot of his work, and it also depicts how Trevor is imagining the integral as a graphic structure.

First he identifies that the minimum area of sine is 0 . It is hard to determine where that information comes from, but it seems like he is using the graph's physical properties first, then trying to explain them. This means that the minimum area of 0 could be determined by things such as the point being at the origin or it could be the thought that the area is 0 as nothing has accumulated yet (although this is shown to not be the case in another context). It is difficult to tell as a solitary thought, but it would go against much of Trevor's reasoning around the integral to be thinking of it as accumulation here and nowhere else. In the next part of his description using hand gestures, Trevor is able to create a wave function that is presumably to represent sine. While this wave function appears to be smooth in its creation in the air, it does not necessarily indicate emergent shape thinking, a process view, or covariational reasoning. This is because the smooth image may just be based on a visualization he has of the graph and is attempting to match.

Next there is some amount of clear covariational reasoning, as Trevor examines how the positive and negative waves would cancel resulting in another 0 point on the integral graph. This reasoning matches with the levels of MA3 or MA4 covariational reasoning, as Trevor is discussing how the area is accumulating by unit increments of waves, and how these waves cancel each other out. After considering the two waves together he considers one wave, choosing 
the maximum point on the integral graph and determining that it matches the area of one sine wave. Additionally, he determines this is the maximum area. Here there is some amount of implication toward continual reasoning about the accumulation function in relation to $\mathrm{x}$, as he is recognizing that one wave is the maximum amount of accumulation, as he states the rate of change shifts to negative area after that.

It can also be argued, however, that this is not MA5 reasoning, and merely MA2 reasoning based on two separate sections. As discussed earlier with concavity, recognition of an inflection point does not necessarily imply understanding of it or covariational reasoning being involved in finding it. It also seems that the splitting of the graph into areas of waves reflects both Trevor's static shape thinking, of fixed areas to be subtracted, and his action view of the function, only describing the areas at the maximum and minimum points that he can easily identify and compare.

This example gives an instance where Trevor could be reasoning at the MA5 level, as he is once again working with a function that has continuous change in the rate of change, yet his description really only goes as far as describing physical properties like area, and specifically chosen points without complete description of what is happening between them. Despite the lack of MA5 reasoning presented, however, Trevor's description of why the integral of sine is a shifted 1-cos is fairly detailed and accurate. When considering his algebraic description, this graphical instance seems to allow Trevor to consider more variation. Since y is no longer necessarily an unknown constant, but possibly a variable, this allows for higher levels of covariational reasoning to be displayed. 


\section{Similarities in covariational reasoning of the derivative and antiderivative}

This section explores how Trevor uses covariational reasoning and pseudo analytical thinking in similar ways for the derivative and antiderivative.

\section{Static shape thinking in the derivative and antiderivative.}

These excerpt focuses on how Trevor's static shape thinking is used instead of possible covariational reasoning of the derivative or integral. This excerpt is showing how he may be using static shape thinking in these instances without it being explicit, and how this shape thinking would be within evidence against MA5 covariational reasoning. These instances also each show cases where Trevor recognizes the continuity of the function that is having its derivative or integral taken, and the continuity of the derivative and integral to some degree, which is useful when considering if he is able to achieve the MA5 level of covariational reasoning.

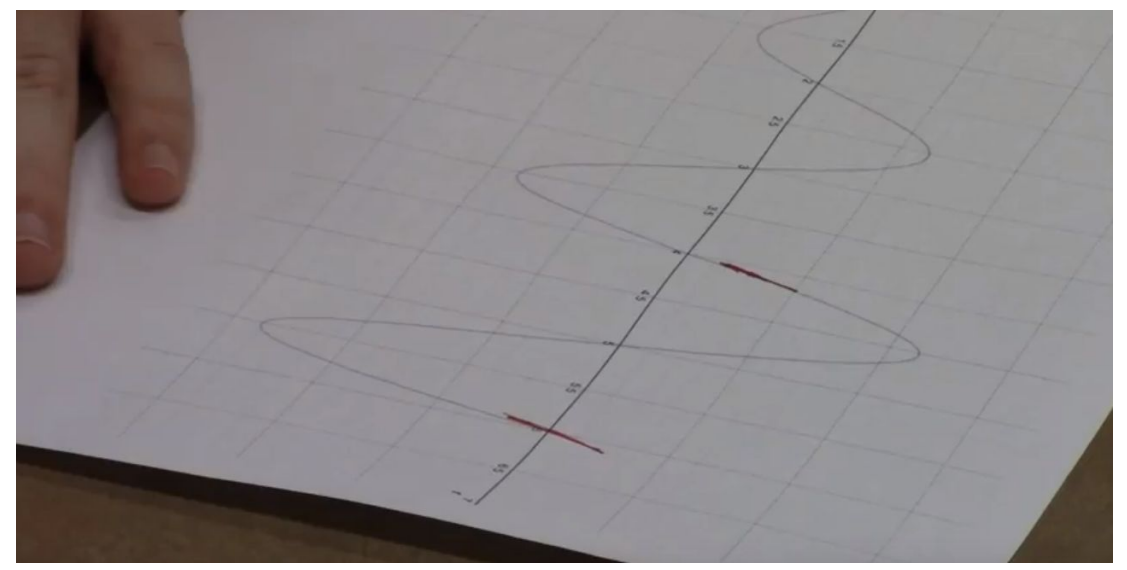

Figure 3. Rates of change of a sine function. Trevor's representations of tangent lines at two different points on the function are shown. 
Excerpt 9: Session 4, November 30, 2017

$R$ : Where is the rate of change the largest?

T: Between 3.5 and 4.5 you have the largest wave and since the peaks and troughs are one apart, so within this largest height or difference somewhere in between will be the steepest point of increase

R: Why not this one?

$T$ : By visually glancing this one looked steeper, if it were to continue the pattern it would go up higher and be taller, but somewhere in here [points past the endpoint of the graph] it would be taller

[16 minutes later]

$R:$ Where is the area of accumulation the highest?

T: The area of accumulation, this tells me that each peak and trough a greater area is being accumulated in the positive or negative, because the area of accumulation is the greatest here [points at top of biggest wave], but the width of the waves are the same, then I know that the rate of accumulation is greatest at the point, in which the peak of little $f(t)$ is occuring.

The first part of the excerpt shows Trevor using reasoning similar to that of MA4 covariational reasoning. This is being done in a task where it would be more appropriate to the task, and explanation of it, to use MA5. This is important to note, as there are other instances where Trevor uses MA4 covariational reasoning it could be effective at solving the task without any other pseudo-analytical thinking or methods being employed. Here Trevor has identified that the peaks and troughs of each respective wave vary by differing amounts each time, and are consistently one apart. This leads to the conception that since these intervals are each the same, the height is the only important factor in the rates of change. Despite the chosen point being the incorrect answer to the task, this decision making process is actually very important to Trevor's view of the derivative. The reason this is crucial is it may be showing some reference to Trevor's understanding of the derivative as a function defined on all the values the function that is in the derivative is defined on.

This leads to a situation where Trevor is more likely to be indicating an emergent view of the derivative and/or the original function. We do see Trevor first examine the average rate of 
change over each peak and trough, then understand that "in between will be the steepest point of increase". This creates an understanding of how there is continuity between these points, and a connection between the average rate of change and the derivative, as opposed to solely referring to a reference like steepness. Unfortunately Trevor's MA4 level of covariational reasoning does not allow him to get the correct answer as he does not consider other intervals smaller than the unit he prescribed, and ignores the last trough to zero average rate of change, and the endpoint of that which is the actual largest instantaneous rate of change. Additionally Trevor's phrasing of the steepest point of increase indicates that he has a static view of the rate of change as steepness in this case, and how steepness at a point is indicative of a tangent line.

Finally, while he is recognizing the existence of changes in steepness throughout the original function, this is only shown at specific points. When he is trying to determine if his initial guess or the actual largest instantaneous rate of change is larger, he has to examine specifically those points compared to each other instead of considering a continuum (for which the pattern could show that the slope in the next wave would be larger). Thus he is not at the MA5 level, as he is still viewing the derivative as an action, not a process, which is necessary to MA5. Additionally by observing the video, it seems Trevor chose the midpoint of the difference of the y values to determine where the largest instantaneous rate of change would be, as opposed to considering an inflection point. Trevor acknowledges that he decided between points based purely on visuals, which is key to the fact that he may not be reasoning about covariation, but instead a visual description of steepness of tangent lines.

The second half of the excerpt is very closely related to the first. Trevor first identifies the unit interval with the largest area. From there Trevor chooses the largest point on the graph 
between those values. There is no direct indication that this is thought of as the largest area of a Riemann sum, or that there is a multiplicative process between $\mathrm{f}(\mathrm{x})$ and $\mathrm{dx}$ at this specific point. Given how close this example seems to the previous, it seems Trevor would likely be reasoning the same way, which would mean that he is using static shape thinking as opposed to covariational reasoning. Important to note is that he is able to get this answer correct, where in the previous example he did not. This shows how the static shape thinking and action view of functions can be effectively used in calculus tasks in many cases, but how slight differences and distinctions would lead to incorrect responses. This shows how MA4 reasoning with added methods that don't involve covariational reasoning can also be used to correctly solve calculus tasks. Conversely, when students have to rely on additional methods or reasoning when attempting to solve calculus tasks, this may or may not be effective based on the exact context.

\section{Composition of derivative and antiderivative.}

Where the previous example described the similarity of covariational reasoning and shape thinking in the integral and derivative, this excerpt show what happens when both of these functions are involved at the same time. Here Trevor is reasoning about how to calculate the average rate of change of an integral, as well as how to find the instantaneous rate of change over a range of values. Much of this discussion reflects findings from Excerpts 2 and 3 working with concavity and rates of change of the quadratic function. 


\section{Excerpt 10: Session 4, November 30, 2017}

$R$ : What is the average rate of change of $F(x)\left[F(x)=\int_{0}^{x} \sin \left(\frac{2 \pi}{3} t\right)\right]$

T: It should be 2.25 over $\pi$, that would be rise and $\pi$ would be run

$R$ : How did you get the rise and the run?

T: Because this is a function of $x$, the $x$ values will be along the $x$ coordinate, my run. The output, which you gave me, of 2.25 is the accumulated area, so going from 0 to 2.25 gives me a height of 2.25 and then from 0 to $\pi$, wait... cosine of 0 is 1 , oops

$R$ : Why did you change it?

T: I know I'm not starting at zero, unless... [thinks]

$R$ : So what does 2.25 represent?

$T: 2.25$ represents the maximum value. It's the total accumulated area of the integral of $\sin \left(\frac{2 \pi}{3}\right)$

$R:$ What do you mean by maximum?

T: [pause] It's our end value, of the integral of sine at $\frac{2 \pi}{3}$, so what I need to know is what the integral of 0 over 0 is and that would get me the exact answer... I suppose I'm phrasing that wrong.. I need to know the integral of $\sin \left(\frac{2 \pi}{3}\right)$ times 0 to find initial value, in order to compute rise over run but since I messed up my work earlier I can't figure that out.

$R$ : Can you tell me the instantaneous rate of change as $x$ varies from 0 to $\pi$ ?

T: I honestly can't think of a way to do that, because any instantaneous rate of change would only give me one tangent line...

[2.5 minutes pass]

$R$ : So what's the instantaneous rate of change as $x$ varies from 0 to pi?

T: I can't think of a way, if I were taking the derivative I would do is put in... rise over run of $\sin \left(\frac{2 \pi}{3}\right)-\sin (0)$ over $\pi-0$.

$R$ : So that would be an average rate of change of the function $\sin \left(\frac{2}{3} t\right)$ from 0 to $\pi$...

T: I can't figure out a way to do a derivative or instantaneous rate of change for a large value, because an instantaneous rate of change is for a very specific point

$R$ : Let $g(x)=x^{2}$, what is the instantaneous rate of change?

T: Big or little $g$, never mind it will be $2 x$

$R$ : So it still has varying $x$ in it, it's not going to be a number

T: Ohh, it's going to be a variable, I guess $\sin \frac{2}{3}$ of $x$

Here Trevor starts by working with the average rate of change of the accumulation

function. Unfortunately earlier before this example Trevor had incorrectly calculated the

indefinite integral when for $\int_{0}^{\pi} \sin \left(\frac{2 \pi}{3} x\right) d x$, which resulted in the researcher providing the answer

of 2.25. As Trevor's last research session the guidance within this session by the researcher was often higher than in other instances. When provided with 2.25 as the answer Trevor goes back to 
his classic view of the average rate of change and decides to calculate rise over run, where he sees the accumulation as 2.25 over a run of $\pi$. Here we see that his way for finding what the run is is linked to the functions input, the $\mathrm{x}$, and the output is representative of the rise or height, which in this case is appropriate to the task unlike Excerpt 1.

Next, however, Trevor confuses what he is finding the average rate of change of, as he confuses the cosine function with the integral of the sine function. He seems to understand what 2.25 represents as an accumulated area, yet does not decide that when accumulating an area from 0 to 0 would give an area of 0 . This shows how Trevor is not clearly thinking of accumulation at all, but really just an area, and if the area is the end value, he cannot picture the start value. This is one difference that can be examined between an emergent or process view of the integral as accumulation as opposed to a static and action view based on area. This results in him feeling like he cannot solve the problem without trying to find the integral, presumably from 0 to 0 , to find the initial value and calculate rise over run.

Next Trevor is asked to work with the instantaneous rate of change over a range of values. Here Trevor cannot picture this because he views the instantaneous rate of change as an action, that gives him a single tangent line not a range of tangent lines. Here, after the 2.5 minutes, Trevor continues his struggles to determine what the instantaneous rate of change over the range would be, and attempts to calculate the average rate of change of the function within the integral. It is possible that Trevor has actually taken the derivative here without realizing it, and taken the average rate of change of the derivative. This could even be true given the next step if he is still possessing an action view of the derivative function, as he still wouldn't think of being able to find an instantaneous rate of change for a range of values based on that. Either way, 
it shows a lack of thinking of the derivative as a continuous output, and/or the integral as a continuous input. Once again Trevor indicates the thought that the instantaneous rate of change is for a singular and specific point, which is a distinction from MA5 covariational reasoning which would recognize continual changes in rate of change for all values of a function.

When given a simpler example $g(x)=x^{2}$, Trevor is able to consider that the instantaneous rate of change is a function in this case, and with researcher guidance that it can be changing and defined for the interval. Additionally he understands the inverse relationship of the integral and derivative enough to calculate the solution. His struggle with the original rate of change of the integral function may also have to do with his persistent confusion on how the variable t contributes to the function and what variable is the input. However, all of this excerpt shows difficulties from MA1 to Ma5 reasoning when both the derivative and antiderivative are involved.

\section{Conclusions}

When considering calculus student's abilities to reason covariationally it is important to see where they do not use this reasoning, and how this limits their mathematical abilities. Considering the goal of modeling the individual student's covariational reasoning I feel as though it has been achieved.This paper has concluded the student reasons primarily using MA4 covariational reasoning and below. In addition, when behaviors imitating MA5 levels of covariational reasoning are displayed by Trevor, he also consistently uses methods of problem solving that are inconsistent with this level of reasoning.

This type of reasoning is described in research by Carlson et al. (2002) as pseudo-analytic 
thinking, and is composed of behaviors that reflected certain levels of covariational reasoning being paired with other methods of problem solving, and an inability to explain certain reasoning in depth consistently with that level. In their research one example of covariational reasoning and pseudo-analytical thinking closely reflected on of Trevor's behaviors. The research done using the covariational framework discussed that a student can describe the concavity of a function based on graphical information, but when probed as to why if they were unable to fully explain their answer it would not be the MA5 level of reasoning and instead be considered that the student's reasoning on the concavity was pseudo-analytical (Carlson et al., 2002). Trevor mirrored this in Excerpt 5, as he had been through steps creating understandings and patterns based on MA1 through MA4, yet was still unable to use this in order to explain the concavity of the function. There are other instances where Trevor used what was described in previous research as pseudo-analytical thinking, and this paper allowed a more in depth approach to Trevor's different ways of thinking pseudo-analytically.

One way in which Trevor's pseudo-analytical thinking could be more closely examined is through what Moore \& Thompson (2015) call static shape thinking. Trevor exemplifies this type of thinking frequently throughout the teaching experiment. One instance of this is when Trevor bases whether or not a graph is a function on the vertical line test, which relies on orientation and is therefore shape thinking. In that excerpt, Trevor is unable to look at the antiderivative as a function until it is no longer sideways. In Excerpt 1 Trevor is reliant on the measurable physical properties of the graph for his solution. In this case Trevor can relate the side lengths of the right triangle in the two diagrams, but there is little indication of him reasoning past the MA2 level of covariational reasoning without needing to physically measure how the sides are changing. 
Additionally, when considering Trevor's understanding of the derivative and average rate of change he consistently relies on shape thinking to describe these functions. The derivative is often viewed by Trevor as a tangent line at a point, even when it is on a unit circle (see Excerpt 6). To him the tangent line does not even represent the covariational reasoning being discussed, as he is no longer comparing the vertical and horizontal axis. This is important to note, as Trevor does not appear to view the derivative as a specific two quantities varying, but instead views it as a physical object. In addition it frequently seems as though the average rate of change is often viewed like this, through secant lines, like in Excerpt 4 where he is reasoning about patterns between average rates of change, but is having difficulties acknowledging which quantities are involved.

On top of his view of the derivative being viewed through tangent lines, his view of the the antiderivative, is most often related more to a conception of area. This is shown in each excerpt where a graph of the antiderivative is used. When considering the area he can often reason in sections of the graph, such as recognizing which positive areas are larger than negative areas in a wave function. This view of the antiderivative as area often tends to limit Trevor's covariational reasoning related to it to MA4 and below.

For Trevor's view of these two calculus functions in non-graphical contexts, similar ideas are shown through the lense of an action view of the functions. For the derivative he consistently describes it as being done at specific points, and often does not attend to what this process is outputting based on the input. This view of the calculus functions makes it difficult for Trevor to consider things like composition of the antiderivative and derivative, as in Excerpt 10, where he does not see an inherent need for the x variable to be part of his functional output. Additionally, 
beyond just viewing the derivative as a tangent line, there is little to no thought of as a representation of covarying quantities, as Trevor seems to likely picture it as too small, or a point, so the change could be thought of as nonexistent.

The antiderivative also seems to be based on an action view for Trevor. Finding the antiderivative for Trevor often seems to be similar to his perception of average rate of change. He takes two values and finds a difference. In the same way his view of average rate of change is not applied on infinitely small intervals through the derivative his view of antiderivative is through specifically sized chunks of area, as opposed to continuous accumulation. This can be shown through his complete lack of acknowledgement that the antiderivative in Excerpt 10 does not start at a value of 1 , but a value of 0 and accumulates from there.

Considering all of this, the suggestion I can make is for educators to consider that there may be students like Trevor in their classroom. While this paper is very limited in generalizability and scope because Trevor is the only student closely examined, it also allowed for the research to be very centered on him, and where his difficulties arose for him. With Trevor as a possible student, or anyone similar to him, an educator must be very careful with their word choice, and ways of description. As found in Carlson et al. (2002), calculus student's tend to struggle and tend to display various kinds of pseudo analytical thinking instead of more complex understandings of the problem. With Trevor this type of pseudo-analytical thought can often be broken into the categories of an action view of a function (Oehrtman et al., 2008) and static shape thinking (Moore \& Thompson, 2015).

When talking about a derivative, or an antiderivative it would be important to emphasize to a student like Trevor that while a tangent line or an area may be representative of the 
functions, this is not the defining nature of them. When teaching a student like Trevor it is important to develop notions of the function being a mapping from input to output as opposed to a function in which one plugs individual inputs to get individual outputs. One consideration for future research I will pose is base on Trevor's pseudo-analytical thinking presenting in these ways and examining if other students primarily share these tendencies. In addition to this it seems important to ask if missing MA5 covariational reasoning in calculus students exists in those without reliance on these alternative methods of problem solving presented as pseudo-analytical thinking. While it is out of the scope of this paper to offer concrete solutions, it is important to see how Trevor's reasoning has changed his ability to view calculus concepts and to consider where his problem solving methods are coming from. 


\section{References}

Boeije, H. (2002). A purposeful approach to the constant comparative method in the analysis of qualitative interviews. Quality and Quantity, 36, 391-409. doi: https://doi.org/10.1023/A:1020909529486

Byerley, C., Yoon, H., \& Thompson, P. W. (2016). Limitations of a "chunky" meaning for slope. In T. Fukawa-Conelly (Ed.), Proceedings of the 19th Meeting of the MAA Special Interest Group on Research in Undergraduate Mathematics Education, Pittsburgh, PA.

Carlson, M., Jacobs, S., Coe, E., Larsen, S., \& Hsu, E. (2002). Applying covariational reasoning while modeling dynamic events. Journal for Research in Mathematics Education, 33(5), $352-378$.

Carlson, M., Oehrtman, M., \& Engelke, N. (2010): The precalculus concept assessment: A tool for assessing students' reasoning abilities and understandings. Cognition and Instruction, 28(2), 113-145.

Johnson, H. L. (2012). Reasoning about variation in the intensity of change in covarying quantities involved in rate of change. Journal of Mathematical Behavior, 31(3), 313-330. doi: https://doi.org/10.1016/j.jmathb.2012.01.001

Moore, K. C., \& Carlson, M. P. (2012): Students' images of problem contexts when solving applied problems. Journal of Mathematical Behavior, 31(1), 48-59. doi: 10.1016/j.jmathb.2011.09.001

Moore, K. C., Paoletti, T., \& Musgrave, S. (2013). Covariational reasoning and invariance among coordinate systems. The Journal of Mathematical Behavior, 32(3), 461-473. doi:10.1016/j.jmathb.2013.05.002

Moore, K. C., \& Thompson, P. W. (2015). Shape thinking and students' graphing activity. In T. Fukawa-Connelly, N. E. Infante, K. Keene \& M. Zandieh (Eds.), Proceedings of the 18th Meeting of the MAA Special Interest Group on Research in Undergraduate Mathematics Education, pp. 782-789. Pittsburgh, PA.

Oehrtman, M., Carlson M., Thompson, P. (2008). Foundational reasoning abilities that promote coherence in students' function understanding. Making the connection: Research and teaching in undergraduate mathematics education, 27-42. Mathematical Association of America, Washington D.C. 
Paoletti, T. \& Moore, K. C. (2017). The parametric nature of two students' covariational reasoning. The Journal of Mathematical Behavior, 48, 137-151. https://doi.org/10.1016/j.jmathb.2017.08.003

Steffe, L. P., \& Ulrich, C. (2014). Constructivist teaching experiment. Encyclopedia of Mathematics Education, 1, 102-109. Berlin: Springer. doi:10.1007/978-94-007-4978-8_32

Thompson, P. W., \& Silverman, J. (2008). The concept of accumulation in calculus. In M. Carlson \& C. Rasmussen (Eds.), Making the connection: Research and teaching in undergraduate mathematics, 117-131. Washington, DC: Mathematical Association of America.

Thompson, P. W. (2012). Advances in research on quantitative reasoning. In R. Mayes, R. Bonillia, L. L. Hatfield \& S. Belbase (Eds.), Quantitative reasoning: Current state of understanding WISDOMe Monographs, 2, 143-148. Laramie, WY: University of Wyoming Press.

Weber, E., \& Thompson, P. W. (2014). Students' images of two-variable functions and their graphs. Educational Studies in Mathematics, 87, 67-85. doi: 10.1007/s10649-014-9548-0 
Appendix A

Oehrtman et al.(2008)'s Descriptions of Process and Action Views of Functions

Action and Process Views of Functions

\begin{tabular}{|l|l|}
\hline \multicolumn{1}{|c|}{ Action View } & \multicolumn{1}{|c|}{ Process View } \\
\hline $\begin{array}{l}\text { A function is tied to a specific rule, } \\
\text { formula, or computation and requires the } \\
\text { completion of specific computations and/or } \\
\text { steps. }\end{array}$ & $\begin{array}{l}\text { A function is a generalized input-output } \\
\text { process that defines a mapping of a set of } \\
\text { input values to a set of output values. }\end{array}$ \\
\hline $\begin{array}{l}\text { A student must perform or imagine each } \\
\text { action. }\end{array}$ & $\begin{array}{l}\text { A student can imagine the entire process } \\
\text { without having to perform each action. }\end{array}$ \\
\hline The "answer" depends on the formula. & The process is independent of the formula. \\
\hline $\begin{array}{l}\text { A student can only imagine a single value } \\
\text { at a time as input or output (e.g., } x \text { stands } \\
\text { for a specific number). }\end{array}$ & $\begin{array}{l}\text { A student can imagine all input at once or } \\
\text { "run through" a continuum of inputs. A } \\
\text { function is a transformation of entire spaces. }\end{array}$ \\
\hline $\begin{array}{l}\text { Composition is substituting a formula or } \\
\text { expression for } x\end{array}$ & $\begin{array}{l}\text { Composition is a coordination of two input- } \\
\text { output processes; input is processed by one } \\
\text { function and its output is processed by a } \\
\text { second function. }\end{array}$ \\
\hline $\begin{array}{l}\text { Inverse is about algebra (switch } y \text { and } x \\
\text { then solve) or geometry (reflect across } \\
y=x \text { ). }\end{array}$ & $\begin{array}{l}\text { Inverse is the reversal of a process that } \\
\text { defines a mapping from a set of output } \\
\text { values to a set of input values. }\end{array}$ \\
\hline $\begin{array}{l}\text { Finding domain and range is conceived at } \\
\text { most as an algebra problem (e.g., the } \\
\text { denominator cannot be zero, and the } \\
\text { radicand cannot be negative). }\end{array}$ & $\begin{array}{l}\text { Domain and range are produced by } \\
\text { operating and reflecting on the set of all } \\
\text { possible inputs and outputs. }\end{array}$ \\
\hline Functions are conceived as static. & Functions are conceived as dynamic. \\
\hline A function's graph is a geometric figure & $\begin{array}{l}\text { A function's graph defines a specific } \\
\text { mapping of a set of input values to a set of } \\
\text { output values. }\end{array}$ \\
\hline
\end{tabular}

